\title{
Pemaknaan Islam Moderat Sebagai Sebuah Terminologi
}

\section{The Meaning of Moderate Islam as a Terminology}

\author{
Dedi Sahputra \\ Program Studi Ilmu Komunikasi, Fakultas Ilmu Sosial Ilmu Politik, \\ Universitas Medan Area, Indonesia
}

Diterima: 03 Juni 2021 Direview: 03 Juni 2021; Disetujui: 14 Agustus 2021 *Coresponding Email: dedi_sahputra@staff.uma.ac.id

\begin{abstract}
Abstrak
Artikel ini bertujuan untuk mengetahui pemaknaan istilah Islam moderat sebagai sebuah terminology. Masalah difokuskan pada tinjauan bahasa dan sejarahnya, serta dari konteks kepentingan politik yang melatarbelakanginya. Guna mendekati masalah, artikel ini yang menggunakan acuan teori terminology. Data-data dikumpulkan melalui tinjauan pustaka dari berbagai penelitian sejenis yang pernah dilakukan. Selanjutnya data yang didapat dianalisis secara kualitatif. Kajian ini menyimpulkan bahwa terjadi bias dalam pemahaman terminologi Islam moderat yang terletak pada penyamaan antara kata "Islam" dengan kata "umat", sehingga istilah "ummatan washatan" kemudian disamakan dengan "Islam moderat". Bias pemaknaan ini dipengaruhi dengan kuat oleh konteks politik global yang berkaitan dengan munculnya istilah terorisme dan konsep globar war on terrorism (GWOT) yang dicetuskan Amerika Serikat pada saat pemerintahan George W.Bush Junior.
\end{abstract}

Kata Kunci: Islam Moderat; Bias Pemaknaan; Konteks Politik Global

\begin{abstract}
This article aims to find out the meaning of the term moderate Islam as a terminology. The problem is focused on reviewing the language and its history, as well as from the context of the political interests that lie behind it. In order to approach the problem, this article uses a reference to the theory of terminology. The data were collected through a literature review of various similar studies that have been conducted. Furthermore, the data obtained were analyzed qualitatively. This study concludes that there is a bias in understanding the terminology of moderate Islam which lies in equating the word "Islam" with the word "ummah", so that the term "ummatan wasatan" is then equated with "moderate Islam". This interpretation bias is strongly influenced by the global political context related to the emergence of the term terrorism and the concept of the global war on terrorism (GWOT) which was coined by the United States during the George W. Bush Junior administration.

Keywords: Moderate Islam; Bias of Meaning; Global Political Context
\end{abstract}

How to Cite: Sahputra, D (2021), Pemaknaan Islam Moderat Sebagai Sebuah Terminologi, Journal of Education, Humaniora and Social Sciences (JEHSS), 4(2), 896-904 


\section{PENDAHULUAN}

Istilah atau terminologi Islam moderat telah menjadi suatu yang menjadi wacana global terutama dalam hubungan umat Islam dengan kelompok agama atau kelompok kepentingan kekuasaan lainnya. Pemaknaan atas terminologi Islam moderat ini kiranya masih beragam, bergantung pada situasi dan kepentingan yang melatarbelakangi pemakanaan terhadap istilah tersebut. Secara umum pemaknaan Islam moderat berkaitan dengan kategorisasi yang dilakukan terhadap kelompok-kelompok yang terbentuk dalam Islam. (1) Fundamentalis yang dianggap ketat memaknai Islam secara tekstual dalam al-Qur'an, (2) Liberalis yang dinilai memberikan ruang logika dalam memaknai hukum Islam, serta (3) Moderat yang dianggap memaknai Islam dengan melihat kandungan al-Qur'an, kaidah syar'iyahnya, maslahahnya, menjadi penengah dengan mempertimbangkan toleransi dalam melihat persoalan sosial.(Hilmi, 2016).

Kategorisasi ini demikian populer dengan pembagian akan wajah Islam secara berjenjang dari yang buruk (fundamentalis), terlalu benar (liberalis) sehingga dianggap tidak berbeda dengan pemikiran di dunia Barat itu sendiri. Sedangkan yang kategori yang ketiga dianggap berada di tengah (moderat). Fundamentalisme yang disebut dalam Islam (sarjana lain menyebutnya Islamisme) dianggap sebagai ide dan reaksi irasional terhadap modernitas yang berhubungan dengan politik, sosial dan ekonomi kontemporer.(Hassan, 2015).

Dalam perspektif para sarjana Barat, Islam moderat menyangkut tentang liberalisasi normal sosial, hermeneutika, pluralisme politik, proses demokrasi, afiliasi organisasi, dan dan pandangan tentang legitimasi negara atas monopoli kekerasan, kemampuan beradaptasi, kesediaan untuk bekerjasama atau berkompromi.(Islam \& Khatun, 2015). Freedman sebagaimana beberapa sarjana lain bahkan tanpa sungkan menghadap-hadapkan antara Islam moderat dengan apa yang disebutnya dengan Islam progresif bahkan Islam konservatif. Dalam kasus Indonesia dan Malaysia, menurutnya, di bawah kondisi yang moderat organisasi kemasyarakatan Islam memainkan peran penting dalam demokrasi.(Freedman, 2009).

Kiranya pemaknaan terhadap Islam moderat yang datang dari Barat ini menjadi arus mainstream pemikiran di tanah air. Para sarjana lokal di Indonesia kemudian banyak yang mendefenisikan Islam moderat dengan merujuk kepada pemahaman sarjana Barat. Irawan misalnya menyamakan Islam moderat dengan dengan Islam wasatiyyah.(Irawan, 2017). Demikian juga Minftahuddin menyebut bahwa Islam yang moderat yang mau menerima dialog tentang peradaban, toleransi, dan kerukunan.(Minftahuddin, 2010). Maka tentu sebaliknya yang dianggap tidak mau menerima dialog tersebut dianggap bukan moderat atau dilabeli dengan stigma tertentu. Moderat didefenisikan sebagai sikap selalu mencari jalan tengah dalam mengatasi masalah. Jalan tengah yang dimaksud adalah tidak mengedepankan sikap dan orang yang disebut moderat digambarkan sebagai orang yang menginginkan perdamaian, kerukunan, dan bukan kekerasan, apalagi konflik yang menumpahkan darah.(Fransisca, 2019). Ni'am bahkan meyakini beragama secara moderat akan memudarkan polarisasi antara fundamentalisme dan sekularisme untuk menghadapi modernitas dan perubahan. Menurutnya, Islam yang berada di tengah (ummatan wasathan) akan membentuk karakter Islam yang demokratis, terbuka, dan rasional.(Ni'am, 2015)

Lebih dari itu, sektor pendidikan tidak terlepas dari pemaknaan akan Islam moderat. Suharto mengatakan bahwa ajaran Islam moderat ini kemudian terlembagakan dalam lembaga pendidikan Islam yang diselenggarakan oleh lembaga-lembaga pendidikan Islam yang khas Indonesia secara pasti mengajarkan kepada peserta didiknya mengenai Islam Indonesia yang moderat.(Suharto, 2017). Manakala Najib menyimpulkan bahwa merujuk pada pola pendidikan Islam Indonesia selalu mengambil jalan tengah (wasațiyyah) dari setiap tantangan yang muncul akibat gerak sejarah. Kesimpulan ini didasarkan pada sistem pendidikan yang digunakan, ilmu yang dipelajari hingga metode yang menggunakan arab pegon sebagai jembatan dari kesenjangan bahasa pengantar, pendidikan madrasah yang mengadaptasi sistem pemerintahan klasikal dari pihak kolonial, serta formalisasi melalui fenomena madrasah negeri, sampai kebijakan mu'adalah dan pendidikan diniyyah formal.(Najib, 2018). Khandaker juga menegaskan bahwa pernyataan yang menyuarakan bahwa Islam perlu direformasi, dan perlu dimulai dari 
Muslim moderat berasal dari para orang-orang liberal, atheis, dan Muslim sekuler termasuk Bill Maher, Ayaan Hirsi Ali, Asra Nomani, and Zuhdi Jasser.(Khandaker, 2017)

Dalam sejarahnya, Islam dimaknai secara berbeda dalam politik luar negeri Indonesia pada masing-masing rezim berkuasa. Di era Soekarno dan Soeharto, Islam hanya dipandang sebagai agama. Di masa rezim Abdurahman Wahid, diwacanakan Islam moderat sebagai proyek politik. Sedangkan wacana ketiga mengartikulasikan Islam moderat sebagai proyek politik dan memasukkannya di bawah panji perang global melawan teror di masa rezim Megawati maupun Susilo Bambang Yudhoyono.(Umar, 2016).

Islam moderat juga dianggap sebagai anti-tesis bagi terminologi yang dianggap negatif seperti politik identitas. Islam moderat dinilai penting sebagai suatu solusi bagi perpecahan yang ada di dalam masyarakat karena sifatnya yang dianggap lebih menekankan pada kepentingan universal dari kepentingan suatu identitas tertentu.(Nawawi, 2019). Islam moderat juga dimaknai sebagai corak Islam yang dapat diterima bagi masyarakat tertentu. Seperti masyarakat yang tinggal di kawasan pendalaman Kalimantan Barat, baik secara geografis maupun sosiologis.(Prasojo et al., 2019).

Artikel ini berupaya menangkap pemaknaan dari terminologi Islam moderat dari berbagai pihak yang dilihat dari tinjauan bahasa dan sejarahnya, serta konteks kepentingan politik yang melatarbelakanginya. Untuk melihat pemaknaan tersebut, artikel ini menggunakan Teori Terminologi yang pertama sekali dikembangkan oleh Eugen Wüster. Faber dan MonteroMartinez mengutip Sager mendefenisikan terminologi adalah studi tentang konsep khusus dan sebutan atau istilah linguistiknya. Terminologi adalah unit pengetahuan khusus sebagai hasil dari perkembangan proses kognitif dan komunikasi di antara para ahli dari komunitas bahasa khusus.(Faber \& Montero-Martínez, 2019).

Terminologi adalah pekerjaan yang berfokus pada deskripsi struktur pengetahuan khusus domain dan bagaimana mereka ditransmisikan dalam konteks komunikatif yang berbeda. Ini juga melibatkan pengorganisasian dan pencatatan tentang arti dan penggunaan istilah dalam sumber-sumber terminologis seperti basis istilah, kamus dan glosarium, yang dapat digunakan untuk decoding teks serta untuk pembuatan teks.(Faber \& Montero-Martínez, 2019).

Dalam bahasa khusus, sebuah makna dirumuskan oleh suatu konsep dan disampaikan kepada orang lain melalui istilah (terminologi). Konsep ini mengacu pada objek dari dalam atau luar objek tersebut. Objek individu bisa konkret dan kuat atau seabstrak rasa sakit yang hanya bisa dirasakan. Konsep bisa mengacu tidak hanya pada benda dan kejadian tetapi juga pada properti dan hubungan. Sebuah konsep, bagaimanapun, hanyalah sebuah mental konstruksi yang berasal dari benda. Untuk mengomunikasikan konstruksi mental itu, sebuah simbol dibuat untuk mewakilinya konsep tersebut, yang biasanya istilah teknis komunikasi.(Nedobity, 1983)

Teori terminologi dikembangkan oleh Eugen Wüster (1898 - 1977) dengan tujuan: Pertama, menghilangkan ambiguitas dari bahasa teknis dengan cara standarisasi terminologi untuk menjadikannya alat komunikasi yang efisien. Kedua, untuk meyakinkan semua pengguna bahasa teknis tentang manfaat terminologi standar. Ketiga, untuk menetapkan terminologi sebagai disiplin untuk semua tujuan praktis dan untuk memberinya status ilmu.

Untuk mencapai tujuan tersebut Wüster menetapkan tiga tugas utama, yaitu: Pertama, pengembangan prinsip internasional yang standar untuk deskripsi dan pencatatan istilah. Kedua, perumusan prinsip-prinsip umum terminologi (terminologielehre) yang awalnya dilihatnya sebagai cabang linguistik terapan tetapi kemudian sebagai bidang studi otonom. Ketiga, pembentukan pusat internasional untuk pengumpulan, penyebaran dan koordinasi informasi tentang terminologi, yang menjadi infoterm, di bawah sponsor Unesco.(Cabré Castellví, 2003).

\section{HASIL DAN PEMBAHASAN}

\section{Tinjauan Bahasa dan Sejarah Islam Moderat}

Referensi dari ajaran Islam yang kerap digunakan dalam mengeluarkan argumentasi tentang Islam moderat adalah nash dalam al-Qur'an pada surah al-Baqarah ayat 143 yang berbunyi:"Dan demikian (pula) Kami telah menjadikan kamu (umat Islam), umat yang adil dan

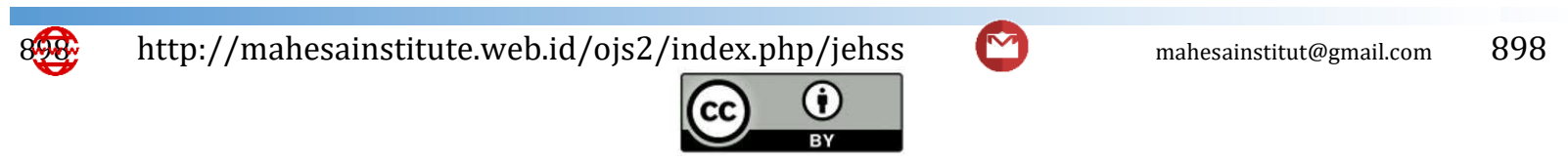


pilihan agar kamu menjadi saksi atas (perbuatan) manusia dan agar Rasul (Muhammad) menjadi saksi atas (perbuatan) kamu".

Al-Asfahaniy menyebutkan kata wasath dengan berbagai derivasinya dalam al-Qur'an berjumlah 3 kali yaitu surat al-Baqarah ayat 143, 238, surat al-Qalam ayat 48.(Nur \& Mukhlis, 2015). Kata wasath dengan berbagai derivasinya inilah yang kemudian dipadankan dengan kata moderat yang kemudian diberi makna pertengahan. Muchtar mengutip Ma'luf menguraikan bahwa istilah al-wasath dalam bahasa Arab adalah isim yang dapat dipakai untuk muzakkar dan muannats, mufrad dan jama'. Karena itu jika kata wasathan diisnadkan pada kata umat maka ia berarti; umat yang seimbang, umat pertengahan, atau umat terbaik.(Muchtar, 2013). Sedangkan menurut Ibnu Asrur kata wasath didefenisikan dengan dua makna. Pertama, secara etimologi kata wasath berarti sesuatu yang ada di tengah, atau sesuatu yang memiliki dua belah ujung yang ukurannya sebanding. Kedua, secara terminologi bahasa makna wasath adalah nilai-nilai Islam yang dibangun atas dasar pola pikir yang lurus dan pertengahan, tidak berlebihan dalam hal tertentu.(Nur \& Mukhlis, 2015).

Sementara itu, Abdurohman mengartikan kata tawassuth dengan kata moderat memaknainya sebagai suatu watak yang merupakan ciri Ahlussunah waljamaah yang paling menonjol. Ciri tersebut bukan satu-satunya, karena masih ada beberapa watak lain yang menjadi cirinya yaitu watak i'tidal (bersikap adil), tawazun (bersikap seimbang), dan tasamuh (bersikap toleran), sehingga ia menolak segala bentuk tindakan dan pemikiran yang ekstrim (tatharruf) yang dapat melahirkan penyimpangan dan penyelewengan dari ajaran Islam.(Abdurrohman, 2018). Pemaknaan dari asal kata ini menunjukkan bahwa istilah-istilah yang berasal dari ajaran Islam al-wasath, tawassuth atau wasathan merupakan bagian dari ajaran Islam. Dengan kata lain, Islam adalah rumah bagi ajaran-ajaran yang membawa keselamatan dunia dan akhirat.

Khandaker mengutip Mahmood Mamdani, menyebutkan pemaknaan Islam yang terjadi dalam perspektif Barat dengan melakukan kategorisasi good Muslim (Muslim baik) dan bad Muslim (Muslim jahat), yang fokus pada narasi konstruksi politik yang melakukan polarisasi antara Muslim Barat dari non Muslim Barat. Wacana kategorisasi Muslim ini berasal dari Bernard Lewis selama menjadi penasihat kebijakan pada pemerintahan Bush.(Khandaker, 2017). Akibat kategorisasi ini menimbulkan kerugian bagi umat Islam, di mana para ulama dan pendakwah yang dianggap tidak menerima konsep Islam moderat mendapat perlakuan berbeda dengan mereka yang dianggap patuh karena menerima konsep moderat. Para ulama dan pendakwah bahkan dipenjara seperti Ustadz Abu Bakar Ba'asyir, Ustadz Alfian Tanjung, Ustadz Maaher At-Thuwailibi, Habib Bahar bin Smith, Habib Rizieq Shihab, Gus Nur.

Ummatan wasathan adalah bagian dari ajaran Islam. Islam sebagai ad-dien tentu berbeda secara makna dan tidak bisa disamakan dengan "umat". Karenanya pemadanan kata "Islam Wasathan" sesungguhnya tidak tepat. Apalagi kemudian disebut dengan "Islam Moderat" sebagai bentuk transliterasinya. Kategorisasi ini secara langsung menyelisih ajaran Islam. Karena tidak ada terminologi "Islam Moderat" atau "Islam Radikal" dalam ajaran Islam. Yang ada adalah kategorisasi Muslim, Kafir, Munafik, Fasik dan seterusnya. Istilah moderat, jika pun ingin dikaitkan dengan Islam atau ajaran Islam, sepertinya lebih tepat dipadankan dengan kata "dakwah", hingga menjadi "dakwah yang moderat".(Sahputra, 2020).

Menurut Adian Husaini, istilah Islam moderat berasal atau diadopsi dari Amerika Serikat. Dari sumbernya ini, defenisi moderat disebutkan tidak berpaham liberal dan tidak ultrakonservatif.(Husaini, 2019). Sedangkan dari sumbernya, istilah-istilah yang berkaitan dengan Islam yang berasal dari Barat, berasal dari kajian para sarjana Barat tentang timur (orient), termasuk di dalamnya tentang Islam.

Kegiatan orientalis sejak lama telah menimbulkan keresahan di dalam umat Islam. Karena para orientalis ini berusaha mengajak umat Islam untuk meragukan agamanya sendiri, bahkan menyudutkan ajaran Islam. Salah satunya seperti yang ditunjukkan oleh Montgomery Watt yang dianggap orientalis moderat. Montgomery Watt menulis bahwa al-Qur'an dan Sunnah mencoba meragukan otentisitas ajaran Islam. Dia menyimpulkan bahwa bahwa beberapa bagian al-Qur'an dan Hadis itu adalah sengaja dibuat dan dia bahkan menuduhnya tidak konsisten. 
Karena kesimpulannya ini, dia mengatakan tidak bisa dijadikan sumber pandangan hidup Islam. Ia bahkan mencurigai adanya "ayat-ayat setan" dalam al-Qur'an.(Zarkasyi, 2009). Helmut Gatje juga mengajukan beberapa tesis negatif tentang al-Qur"ân. Dalam bukunya The Qur'ân and Its Exegesis, Gatje menganggap ayat-ayat non-wahyu telah masuk ke dalam mushaf al-Qur"ân, sedangkan ayat-ayat wahyu justru tidak dimasukkan ke dalamnya.(Hamim, 2013).

Dari keseluruhan gerakan orientalisme dalam berbagai bentuknya dari awal hingga akhir ini, Edward Said menyimpulkan bahwa orientalisme itu lebih merupakan gambaran tentang pengalaman manusia Barat ketimbang tentang manusia Timur; Orientalisme telah menghasilkan gambaran yang salah tentang kebudayaan Arab dan Islam; dan meskipun kajian orientalis nampak objektif dan tanpa kepentingan, namun ia berfungsi untuk tujuan politik.(Zarkasyi, 2009). Dengan kata lain, orientalis berasal dari sudut pandang Barat untuk mempelajari yang lain (the other), atau dalam perspektif yang lain, adalah untuk "mengajari" yang lain yang dianggap terbelakang.

Dari uraian di atas menunjukkan bahwa istilah wasathan dan moderat sebagai dua istilah yang sering dipadankan sebagai memiliki arti yang sama, namun sesungguhnya berasal dari sumber yang berbeda baik secara makna asal maupun konteks sejarahnya. Istilah wasathan lahir dari ajaran Islam sebagai sebuah istilah yang diturunkan dari langit sebagai petunjuk bagi umat manusia. Istilah wasathan ini dari sumber aslinya dalam al-Qur'an surah al-Baqarah ayat 143 dipadankan dengan kata ummatan sehingga menjadi ummatan washatan. Sedangkan moderat adalah bahasa yang diserap dari bahasa Inggris yang berasal dari kata moderate. Dalam Oxford Learner's Dictionaries, moderate sebagai kata sifat bermakna: that is neither very good, large, hot, etc. nor very bad, small, cold, etc. Sedangkan moderate sebagai kata benda bermakna: a person who has opinions, especially about politics, that are not extreme. Kesamaan pada posisi tengah dari makna washatan dan moderate. Tetapi ketika memadankan kata moderate atau moderat dengan kata Islam adalah suatu yang tidak memiliki alasan secara bahasa dan menimbulkan bias makna dan memiliki dampak secara politik.

\section{Konteks Kepentingan Politik Islam Moderat}

Peristiwa dua pesawat yang dibajak dan menabrakkan diri ke gedung terbesar di New York, yaitu gedung World Trade Center (WTC) pada tanggal 11 September 2001, telah menandai dimulainya fokus pada terorisme, baik dalam politik domestik maupun internasional. Pihak berwenang Amerika Serikat kemudian mengumumkan bahwa pihak yang menjadi tersangka adalah jaringan kelompok yang bernama Al Qaeda yang didukung oleh rezim Taliban di Afghanistan. Penyebutan al Qaeda dan Talibat selanjutnya merujuk pada Islam di seluruh dunia.

Sejak peristiwa itu pula pemerintah Amerika Serikat yang dipimpin oleh George Walker Bush sebagai presiden memulai perang untuk melawan teroris. Perang yang dimaksud tidak saja bermakna lokal dan dalam posisi bertahan, namun mengajak seluruh dunia untuk berperan memerangi terorisme dan bertindak secara agresif dengan melakukan apa yang disebut dengan menghancurkan basis terorisme dunia. Global War on Terror (GWOT) ini juga diikuti dengan pembentukan aliansi global untuk memerangi terorisme serta munculnya bantuan keamanan AS untuk negara-negara yang terlibat dalam agenda global tersebut. Dengan kata lain, peristiwa WTC yang dikenal dengan peristiwa 9/11 tidak hanya mengubah kebijakan luar negeri AS, tetapi juga politik global yang lebih luas.

George W. Bush mengirim pesan yang kuat ke negara-negara Muslim dengan bernada ancaman. Dia mengatakan "Over time it's going to be important for nations to know they will be held accountable for inactivity. You're either with us or you're against us in the fight against terror" (Seiring waktu, penting bagi negara-negara untuk mengetahui bahwa mereka akan dimintai pertanggungjawaban atas ketidakaktifan. Anda bersama kami atau Anda melawan kami dalam perang melawan teror"

Amerika Serikat secara terbuka kemudian memberi dukungan kepada negara-negara yang ikut dalam GWOT dengan memberikan sejumlah dana yang disalurkan melalui berbagai lembaga swadaya masyarakat (LSM). Sebagian besar pendanaan dari Amerika Serikat itu mengalir kepada 
LSM yang berafiliasi kepada Islam. Tujuan dari dukungan pendanaan ini adalah untuk mengampanyekan Islam moderat terutama di kalangan umat Islam.

Amerika Serikat ingin melihat kelompok moderat dan progresif berhasil mendorong progressive pluralisme dan toleransi yang lebih besar. Sebagai bagian dari perang melawan teror, pemerintah AS telah meningkatkan upaya diplomasi publik internasional dan telah meningkatkan pendanaan untuk Departemen Luar Negeri dan USAID. Sebagian dari uang ini digunakan untuk organisasi seperti Asia Foundation dan LSM lainnya, dan beberapa organisasi Barat memiliki dana sendiri dan juga bekerja dengan LSM Islam untuk mempromosikan demokratisasi.(Freedman, 2009)

Para sarjana kemudian membagi peta baru GWOT ini dengan mendefinisikan wacana baru dalam politik global, dengan membagi dunia dalam istilah "sekutu AS" dan "musuh AS".(Umar, 2016). Dalam konteks inilah kemudian ketika GWOT datang ke Islam, terciptalah kategorisasi "Muslim yang Baik" dan "Muslim yang Buruk", yang didasarkan pada subjektivitas liberal dan kepentingan politik AS.(Mamdani, 2002).

Pertanyaan selanjutnya adalah bagaimana dengan posisi Indonesia dalam kaitan GWOT dan kampanye Islam moderat ini? Indonesia sebagai negara demokrasi terbesar ketiga di dunia setelah India dan Amerika Serikat dan negara dengan populasi Muslim terbesar di dunia menyiratkan betapa penting dan strategisnya partai politik sebagai instrumen utama demokrasi dan juga peran agama Islam.(Sahputra, 2016b). Oleh karenanya Indonesia sebagai sebuah negara akan menjadi perhatian dalam kehidupan internasional, terutama yang berkaitan dengan perkembangan politik global. Akan ada dua pilihan mainstraem dalam sikap politik di dalam negeri maupun politik internasional Indonesia yang berkaitan dengan GWOT dan kampanye Islam moderat. Pilihan pertama adalah memegang teguh identitas Islam dan menjadi rujukan dalam kehidupan berbangsa dan bernegara. Kedua, menyesuaikan bentuk Islam di tanah air dengan perkembangan politik global seperti GWOT.

Secara ideal sikap politik suatu negara merujuk kepada kehendak rakyat yang ada di dalam negara tersebut. Dalam hal ini konsep Islam moderat semestinya harus sesuai dengan keinginan mayoritas umat Islam di Indonesia. Karena penilaian publik sebagai konstituen akan menjadi penentuan terhadap suatu tujuan politik.(Sahputra, 2019). Baik Islam sebagai agama maupun partai politik Islam sebagai bagian dari organ demokrasi yang membawa nama Islam sama-sama memiliki keterkaitan dengan publik.(Sahputra, 2016a).

Menteri Luar Negeri Hassan Wirajuda pada paparan Refleksi tahun 2003 dan Proyeksi tahun 2004 di Jakarta, 6 Januari 2004 mengatakan bahwa sebagai negara dengan penduduk Muslim terbesar di dunia Indonesia memikul kewajiban untuk memproyeksikan wajah Islam yang sebenarnya, yaitu Islam yang moderat.(Andriasanti, 2014). Hassan Wirajuda menjabat Menteri Luar Negeri Indonesia sejak tahun 2001 hingga 2009. Ia menjabat dalam dua kabinet, Kabinet Gotong Royong (2001-2004) dan Kabinet Indonesia Bersatu (2004-2009). Pernyataan Hassan Wirajuda tentang Islam moderat tersebut disampaikan saat menjadi Menteri Luar Negeri dalam pemerintahan Megawati Soekarnoputri dan menjelang kepemimpinan Susilo Bambang Yudhoyono (2004-2014). Ekspresi kemoderatan Islam ini dapat ditemukan pada beberapa kesempatan seperti Bali Democracy Forum (BDF), World Movement for Democracy, Parliamentary Union Of OIC Member States (PUIC), dan International Conference on Global Movement of Moderates. Tendensi demokrasi dan Islam moderat sepertinya merupakan upaya Indonesia untuk mendekatkan diri dengan negara demokrasi maju, khususnya Barat.(Andriasanti, 2014). Warisan dari rezim pemerintahan Megawati tersebut dilanjutkan oleh Susilo Bambang Yudhoyono, hingga rezim pemerintahan Joko Widodo saat ini. 




Gambar 1. Proses Istilah Islam Moderat

Dalam hal ini pemaknaan istilah Islam moderat juga dipengaruhi dengan kuat oleh GWOT yang mengucurkan dana yang besar untuk mencapai tujuannya. Di antara tujuannya dapat disimpulkan sebagai menghilangkan ambiguitas dari istilah Islam moderat agar dimaknai sebagaimana dunia Barat memaknainya. Selanjutnya upaya ini juga terkait dengan menjadikan pemaknaan dunia Barat terhadap istilah Islam moderat sebagai standar dalam penggunaannya secara teknis. Tujuan atas standarisasi pemaknaan ini dikampanyekan melalui berbagai LSM maupun lembaga yang dibentuk di perguruan tinggi yang berfungsi sebagai pembentukan pusat pengumpulan, penyebaran dan koordinasi informasi tentang terminologi Islam moderat.

Bias makna dalam istilah Islam moderat ini kemudian berdampak juga pada implementasinya di berbagai sektor, termasuk di sektor pendidikan. Ni'am misalnya menyimpulkan bahwa perlu menghadirkan Islam sebagai ajaran universal yang memberikan arah perdamaian; perlu menggalang aksi penolakan sikap kekerasan dan terorisme; dan saatnya menumbuhkan karakter religius yang moderat. Memahami dinamika kehidupan secara terbuka, menerima kemajemukan.(Ni'am, 2015). Pemaknaan seperti ini dapat dikatakan keliru jika pada sisi yang lain mengakui bahwa Islam adalah ajaran yang membawa rahmat bagi seluruh alam. Karena apabila Islam tidak universal dan tidak mengajarkan perdamaian, tidak menerima perbedaan, melakukan aksi kekerasan, tentu Islam bukan rahmat bagi seluruh alam. Selanjutnya apabila ada apabila ada kelompok yang tidak mengajarkan perdamaian, tidak menerima perbedaan, dan melakukan aksi kekerasan, tentu mereka bukanlah Islam.

Tabel 1: Istilah Islam Moderat sebagai Produk Global

\begin{tabular}{|c|c|c|c|}
\hline No. & $\begin{array}{c}\text { Mereduksi } \\
\text { Ambiguitas }\end{array}$ & $\begin{array}{c}\text { Standarisasi } \\
\text { Istilah }\end{array}$ & $\begin{array}{c}\text { Kampanye } \\
\text { Global }\end{array}$ \\
\hline 1. & Aktivitas orientalis & $\begin{array}{l}\text { Publikasi karya ilmiah, dan } \\
\text { buku-buku }\end{array}$ & $\begin{array}{c}\text { Pendanaan global untuk } \\
\text { LSM dan lembaga moderat }\end{array}$ \\
\hline 2. & $\begin{array}{c}\text { Dikembangkan pemikiran } \\
\text { para sarjana }\end{array}$ & $\begin{array}{c}\text { Kegiatan internasional, } \\
\text { transnasional, dan nasional }\end{array}$ & $\begin{array}{l}\text { Mengoordinir pastisipasi } \\
\text { global }\end{array}$ \\
\hline 3. & $\begin{array}{c}\text { Mempengaruhi kebijakan } \\
\text { pemerintahan }\end{array}$ & $\begin{array}{c}\text { Menekan kelompok yang } \\
\text { menentang Islam moderat }\end{array}$ & $\begin{array}{l}\text { Rekayasa sosial dukungan } \\
\text { pendidikan agama Islam }\end{array}$ \\
\hline
\end{tabular}

\section{KESIMPULAN}

Dari akar katanya, ummatan washatan atau umat pertengahan dan menjadi saksi bagi umat yang lain, adalah salah satu ajaran Islam dan menjadi pemahaman yang disepakati para ulama dan para sarjana Muslim. Selanjutnya terjadi bias dalam pemahaman termonologi Islam moderat yang terletak pada penyamaan antara Islam dengan umat, sehingga ummatan washatan 9.्दू http://mahesainstitute.web.id/ojs2/index.php/jehss

(v) mahesainstitut@gmail.com 902

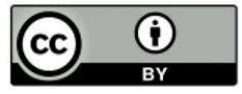


disamakan dengan Islam moderat. Karena Islam adalah nama yang disematkan untuk ajaran dunia dan akhirat yang telah disepakati sebagai ajaran memberikan rahmat bagi seluruh alam. Bias pemaknaan terminologi ini berdampak secara politik dan penyimpangan terhadap makna Islam itu sendiri. Bias pemaknaan tersebut berasal dari perubahan bentuk dari sumber asli dalam al-Qur'an yaitu ummatan washatan yang digandengkan dengan istilah yang berasal dari dunia Barat yaitu moderat. Perubahan ini dengan melalui proses dari kata ummatan washatan kemudian dilafazkan dengan Islam washatan, kemudian dipadankan dengan istilan Islam moderat.

Kebijakan politik global GWOT telah menjadi tolak ukur bagi terminologi Islam moderat. Dengan kata lain, rumusan konsep Islam moderat merujuk pada kepentingan politik global GWOT di bawah kendali Amerika Serikat sebagai negara kuat secara ekonomi dan militer. Secara politik pilihan identitas Islam moderat adalah posisi aman dalam pergaulan dunia internasional, namun pada saat lain memberi dampak pada Islam dan umat Islam. Terminologi Islam moderat berpotensi menyudutkan ulama-ulama tertentu yang tidak segaris dengan kebijakan politik global dengan label tidak moderat, dan pada saat yang menjuluki dan menyanjung ulama tertentu yang dianggap sejalan dengan kebijakan politik global.

\section{DAFTAR PUSTAKA}

Abdurrohman, A. A. (2018). Eksistensi Islam Moderat Dalam Perspektif Islam. Rausyan Fikr: Jurnal Pemikiran Dan Pencerahan, 14(1), 29-41. https://doi.org/10.31000/rf.v14i1.671

Andriasanti, L. (2014). Identitas Islam Moderat dalam Kebijakan Luar Negeri Indonesia. Global: Jurnal Politik Internasional, 16(1), 84-101. https://doi.org/10.7454/global.v16i1.7

Cabré Castellví, M. T. (2003). Theories of terminology. International Journal of Theoretical and Applied Issues in Specialized Communication, 9(2), 163-199. https://doi.org/10.1075/term.9.2.03cab

Faber, P., \& Montero-Martínez, S. (2019). Terminology. The ASHA Leader, 24(6), 1-38. https://doi.org/10.1044/leader.ppl.24062019.28

Fransisca, M. (2019). Moderat Antar Umat, Organisasi dan Pendidikan. JUSPI (Jurnal Sejarah Peradaban Islam), 3(1), 85-92. https://doi.org/10.30829/juspi.v3i1.4375

Freedman, A. L. (2009). Civil Society, Moderate Islam, and Politics in Indonesia and Malaysia. Journal of Civil Society, 5(2), 107-127. https://doi.org/10.1080/17448680903154907

Hamim, T. (2013). Menguji autentisitas akademik orientalis dalam studi islam. Teosofi: Jurnal Tasawut Dan Pemikiran Islam, 3(2), 410-435.

Hassan, I. H. (2015). Orientalism and Islamism : A Comparative Study of Approaches to Islamic Arts and Social Sciences Journal Orientalism and Islamism: A Comparative Study of Approaches to Islamic Studies. January, 4-7. https://doi.org/10.4172/2151-6200.100091

Hilmi, D. (2016). Mengurai Islam Moderat sebagai Agen Rahmatan Lil 'Alamin. In M. Zainuddin \& M. I. Esha (Eds.), Islam Moderat Konsepsi, Interpretasi, dan Aksi (pp. 59-77). UIN-Maliki Press.

Husaini, A. (2019, October 9). Adian Husaini Jelaskan Beda Moderat Versi Islam dan Barat. Republika.Co.Id. https://republika.co.id/berita/dunia-islam/islam-nusantara/19/10/09/pz3ibq320-adian-husainijelaskan-beda-moderat-versi-islam-dan-barat

Irawan, M. D. (2017). Islam Wasatiyyah,Refleksi Antara Islam Modern Dan Upaya Moderasi Islam. TAJDID: Jurnal Ilmu Ushuluddin, 16(2), 111-128.

Islam, T., \& Khatun, A. (2015). "Islamic Moderation" in Perspectives: A Comparison Between Oriental and Occidental Scholarships. International Journal of Nusantara Islam, 3(2), 69-78. https://doi.org/10.15575/ijni.v3i2.1414

Khandaker, L. (2017). Politicizing Muslims : Constructing a 'Moderate' Islam. Connecticut College New London.

Mamdani, M. (2002). Good Muslim, Bad Muslim: A Political Perspective on Culture and Terrorism. American Anthropologist, 104(3), 766-775.

Minftahuddin, M.-. (2010). Islam Moderat Konteks Indonesia Dalam Perspektif Historis. MOZAIK: Jurnal Ilmu-Ilmu Sosial Dan Humaniora, 5(1), 41-54. https://doi.org/10.21831/moz.v5i1.4338

Muchtar, M. I. (2013). "Ummatan Wasathan" Dalam Perspektif Tafsir Al-Tabariy. Jurnal Perspektif IlmuIlmu Agama Konteporer, 2(2), 113-129. https://journal.unismuh.ac.id/index.php/pilar/article/view/455/397

Najib, A. (2018). Patterns of Islamic Education Moderation in Indonesian History. Didaktika Religia, 6(1), 107-124. https://doi.org/10.30762/didaktika.v6i1.1097 
Nawawi, A. M. N. (2019). Dakwah Islam Moderat dan Realitas Politik Identitas dalam Masyarakat Meme. Jurnal Bimas Islam, 12(1), 69-92. https://doi.org/10.37302/jbi.v12i1.100

Nedobity, W. (1983). The General Theory of Terminology: A Basis for the Preparation of Classified Defining Dictionaries. Dictionaries: Journal of the Dictionary Society of North America, 5(1), 69-75. https://doi.org/10.1353/dic.1983.0000

Ni'am, S. (2015). Pesantren: The miniature of moderate Islam in Indonesia. Indonesian Journal of Islam and Muslim Societies, 5(1), 111-134. https://doi.org/10.18326/ijims.v5i1.111-134

Nur, A., \& Mukhlis, L. (2015). Konsep Wasathiyah dalam Al-Quran (Studi Komparatif antara Tafsir al-Tahrîr wa at-Tanwîr dan Aisar at-Tafâsîr). An-Nur, 4(2), 205-225.

Prasojo, Z. H., Elmansyah, E., \& Haji Masri, M. S. (2019). Moderate Islam and the Social Construction of Multi-Ethnic Communities. Indonesian Journal of Islam and Muslim Societies, 9(2), 217-239. https://doi.org/10.18326/ijims.v9i2.217-239

Sahputra, D. (2016a). Content Analysis Pemberitaan Partai Politik Islam Di Pemilu Legislatif 2014. Analytica Islamica, 5(1), 41-54. http://jurnal.uinsu.ac.id/index.php/analytica/article/view/479/0

Sahputra, D. (2016b). Komunikasi Politik Partai Politik Islam. Orbit.

Sahputra, D. (2019). Politik Dan Media Massa dalam Dinamikanya Dengan Pendapat Umum, Komunikasi Massa, Komunikasi Politik Dan Media Massa (I. Rauf (ed.)). PWI Pusat.

Sahputra, D. (2020, September 8). Dari Islam Moderat ke Komunikasi Moderat.pdf. Waspada/Id. https://waspada.id/al-bayan/dari-islam-moderat-ke-komunikasi-moderat/

Suharto, T. (2017). Indonesianisasi Islam: Penguatan Islam Moderat dalam Lembaga Pendidikan Islam di $\begin{array}{lllll}\text { Indonesia. Al-Tahrir: Jurnal } & \text { Pemikiran }\end{array}$ https://doi.org/10.21154/altahrir.v17i1.803

Umar, A. R. M. (2016). A Genealogy of Moderate Islam: Governmentality and Discourses of Islam in

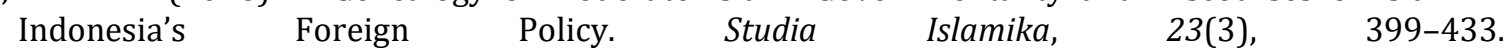
https://doi.org/10.15408/sdi.v23i3.3157

Zarkasyi, H. F. (2009). Liberalisasi Pemikiran Islam: Gerakan Bersama Missionaris, Orientalis dan Kolonialis. Tsaqafah, 5(1), 1. https://doi.org/10.21111/tsaqafah.v5i1.145 